\title{
CONHECIMENTO E UTILIZAÇÃO DE MEDIDAS DE PRECAUÇÃO- PADRÃO POR PROFISSIONAIS DE SAÚDE
}

\author{
Knowledge and utilization of standard precaution measures by health professionals \\ Conocimiento y utilización de medidas de precaución patrón entre los profesionales \\ de salud
}

Livia Melo Villar ${ }^{4}$

\section{RESUMO}

0 objetivo deste trabalho foi descrever o conhecimento sobre medidas de precaução-padrão (MPP), bem como analisar a sua utilização entre 266 profissionais de saúde do Estado do Rio de Janeiro. Foi utilizado um questionário autoaplicável com três domínios: A - Identificação e capacitação profissional; B - Conhecimento e suporte após acidente biológico; C - Utilização de MPP em atividades profissionais. Na população estudada, $174(65,4 \%)$ relataram ter feito nos últimos dois anos algum curso de atualização em sua área, 106 (39,8\%) fizeram algum curso contendo temas de biossegurança, e 31,9\% relataram acidente de trabalho anteriormente. Observamos que os acidentados tinham maior mediana de idade e tempo de conclusão de curso. Concluímos que a maioria dos profissionais reconhece e utiliza as principais MPPs, porém uma parcela desta população ainda não utiliza estas medidas. É importante a capacitação em biossegurança a fim de minimizar o risco durante a atividade profissional.

Palavras-chave: Conhecimento. Biossegurança. Profissional de saúde.

\begin{abstract}
El objetivo de este estudio fue describir los conocimientos acerca de las medidas de precauciones patrón (MPP) y analizar su uso entre los 266 profesionales de salud del Estado de Rio de Janeiro. Se utilizó un cuestionario autoadministrado con tres dominios: A - Identificación y formación profesional; B - Conocimiento y apoyo después de accidente biológico, $\mathrm{C}$ - Uso del MPP en las actividades profesionales. En esta población, $174(65,4 \%)$ informaron que habían hecho en los últimos dos años un curso en su área, 106 $(39,8 \%)$ que lograron algunos cursos que contienen temas de bioseguridad, y el 31,9\% relataron accidente de trabajo anteriormente. Se observó que las víctimas tenían una edad mediana y mayor tiempo de ejecución. Se concluye que la mayoría de los profesionales reconocen y utilizan el MPP clave, pero una parte de la población todavía no utiliza estas medidas. Es importante la formación en bioseguridad con el fin de minimizar los riesgos durante su actividad profesional.
\end{abstract}

Palabras-claves: Conocimiento. Bioseguridad. Profesional de la salud.

\section{Resumen}

The aim of this study was to describe knowledge about standard precautions (MPP) and analyze its usage among 266 health professionals from the State of Rio de Janeiro. We used a selfadministered questionnaire with three domains: A - Identification and vocational training; B-Knowledge and support after biological accident, C-Use of MPP in professional activities. In this population, 174 (65.4\%) reported having done in the last two years a course in your area, $106(39.8 \%)$ made some progress containing matters of biosecurity, and $31.9 \%$ reported work-related accident previously. We observed that the victims had a higher median age and time of completion. We conclude that most professionals recognize and use the key MPPs, but a part of the population still does not use these measures. It is important training in biosafety in order to minimize risk during their career.

Keywords: Knowledge. Exposure to Biological Agents. Health professions. 


\section{INTRODUÇÃO}

Os profissionais de saúde podem estar expostos a diferentes riscos físicos, químicos, biológicos, ergonômicos e de acidentes. Os riscos são compreendidos como processos que decorrem das condições inerentes ao ambiente ou ao próprio processo operacional das diversas atividades profissionais, cabendo ao homem a atribuição de desenvolver, por meio de metodologias baseadas em tecnologia, a capacidade de interpretá-los e analisá-los para a prevenção de acidente. ${ }^{1}$ Com o surgimento da síndrome de imunodeficiência adquirida (Acquired Immunodeficiency Syndrome ou AIDS), maior ênfase passou a ser dada à exposição destes profissionais ao sangue, além de despertar para uma discussão mais aprofundada das relações de trabalho e, sobretudo, das formas de transmissão doenças de risco ocupacional. 2,3,4

Os riscos de exposição a HIV (Human Immunodeficiency Virus), HBV (Hepatitis B Virus) e HCV (Hepatitis C Virus) são proporcionais ao manuseio de objetos perfurocortantes e fluidos orgânicos. 0 risco de aquisição de HCV depois de um acidente ocupacional percutâneo é de 1,8\%, variando de 1 a 10\%. Para o HBV, quando o paciente-fonte é $\mathrm{HBeAg}$ (Hepatitis $B$ Virus e Antigen) positivo, o risco estimado está entre 6 e $30 \%$, e pode alcançar $40 \%$ se as medidas profiláticas não forem realizadas. Já em relação ao HIV, quando o paciente-fonte é positivo, a taxa de risco varia de 0,3 a 0,5\%, sendo $0,09 \%$ após exposição à membrana mucosa. ${ }^{5}$

As medidas de prevenção dos acidentes são divididas em medidas pré e pós-exposição. As medidas de precauçãopadrão (MPP) são consideradas um conjunto de medidas adotadas como forma eficaz de redução dos riscos aos quais os profissionais de saúde estão expostos. ${ }^{6}$ Dentre as MPPs estão incluídas: lavagem de mãos, uso de equipamentos de proteção individual (EPI) e de proteção coletiva (EPC), manejo adequado de resíduos dos serviços de saúde e imunização. ${ }^{6} \mathrm{~A}$ aplicação dessas medidas é recomendada em todos os procedimentos realizados pelos profissionais de saúde, pois limitam a propagação de micro-organismos devida à manipulação segura de artigos e superfícies.?

De acordo com a Organização Internacional do Trabalho (OIT), todos os anos, cerca de 330 milhões de trabalhadores são vítimas de acidentes de trabalho em todo o mundo, além de 160 milhões de novos casos de doenças ocupacionais. Sobre as mortes, a OIT aponta mais de 2 milhões relacionadas ao trabalho: 1.574 .000 por doenças, 355.000 por acidentes e 158.000 por acidentes de trajeto ${ }^{8}$ (Segurança no Trabalho, 2010).

No Brasil, durante 0 ano de 2007, foram registrados no INSS cerca de 653,1 mil acidentes do trabalho. Comparado com 2006, o número de acidentes de trabalho aumentou $27,5 \%$. Do total de acidentes registrados, os acidentes típicos representaram $80,7 \%$ do total de acidentes registrados; os de trajeto, $15,3 \%$; e as doenças do trabalho, $4 \%$. Em relação à categoria profissional, técnicos de nível médio em saúde contribuíram com 4,7\% dos acidentes relatados, porém 21,3\% dos casos notificados não indicaram sua categoria profissional. Deste modo, o número de acidentes em profissionais de saúde pode ser relativamente maior do que foi notificado?.

Neste contexto, foi criada por meio da Portaria ${ }^{\circ} 485$, de 11 de novembro de 2005, a Norma Regulamentadora 32 (NR 32), que trata da segurança e saúde no trabalho em serviços de saúde. A finalidade da NR 32 é estabelecer as diretrizes básicas para que os estabelecimentos de saúde possam implementar medidas de proteção à segurança e à saúde dos profissionais de saúde, bem como daqueles que exercem atividades de promoção e assistência à saúde em geral, medidas que visam à diminuição dos acidentes ocupacionais. ${ }^{10}$ Apesar da existência da NR-32, muitos profissionais continuam se acidentando, provavelmente devido ao desconhecimento das principais MPPs. Dentro deste contexto, torna-se necessário avaliar o conhecimento dos profissionais de saúde para que medidas de conscientização sobre o uso de MPPs possam ser tomadas. Deste modo, o objetivo deste estudo foi descrever o conhecimento de profissionais de saúde do Estado do Rio de Janeiro acerca das MPPs, bem como analisar a sua utilização.

\section{METODOLOGIA}

Desenho do estudo: Com o intuito de obter um retrato das práticas quanto às medidas de biossegurança para geração de subsídios voltados para o desenvolvimento de estratégias de prevenção de acidentes ocupacionais nessa amostra, foi elaborado um estudo descritivo, de abordagem quantitativa, e com delineamento transversal, tendo como instrumento de coleta de dados um questionário (Figura 1) com três domínios ( $\mathrm{A}$ Identificação e capacitação profissional; $B$-Conhecimento e suporte após acidente biológico; $\mathrm{C}$ - Utilização de MPP em atividades profissionais), com questões dos tipos abertas, fechadas e mistas, enfocando, principalmente, o conhecimento dos profissionais de saúde acerca das MPP e sua utilização durante suas atividades.

População de Estudo: Após elaboração do questionário, os sujeitos da pesquisa foram selecionados em uma amostra de profissionais de saúde de três cidades do Estado do Rio de Janeiro em um cenário de recrutamento mais fácil e abrangente (em relação às diferentes categorias profissionais) desses sujeitos, como quando da realização de cursos de especialização de análises clínicas e atualização em saúde.

Do total de indivíduos $(n=325)$ que participaram de cursos de especialização de análises clínicas e atualização em saúde nas cidades de Itaperuna, Campos dos Goytacazes e Rio de Janeiro no período de janeiro a maio de 2008, uma amostra de 266 profissionais concordou em participar do estudo e responderam ao questionário. 0 questionário era anônimo, estruturado e foi administrado por um discente e dois docentes do Curso de PósGraduação em Análises Clínicas da Faculdade Redentor (Itaperuna, RJ). 0 formulário continha apenas um número de ordem distinto para cada participante. A composição da amostra foi apresentada, com base nas variáveis estudadas, na Tabela 2 . 
Como critérios de inclusão foram adotados os seguintes: ser profissional da saúde, de qualquer um dos sexos, de qualquer etnia e ter idade variando entre 18 e 70 anos. Como critério de exclusão: não concordância em responder ao questionário.

Coleta e armazenamento de dados: A coleta de dados foi feita mediante a utilização de um questionário de forma consecutiva ao longo de cada curso, ou seja, não periódica, de forma a proporcionar um ritmo adequado e favorável à coleta de dados durante aquele período. Informações sobre vacinação contra hepatite $B$ e resposta vacinal (pelo teste anti-HBs ou anticorpo contra o antígeno de superfície do vírus da hepatite B) foram consideradas neste estudo para avaliação de fator de proteção dos profissionais de saúde contra a hepatite B no exercício de sua profissão. As variáveis categóricas foram codificadas através de números e, juntamente com as variáveis quantitativas, armazenadas em uma pasta de trabalho criada no Microsoft Office Excel 2007 (Microsoft Corporation, EUA), utilizando-se a ferramenta de dados. Na construção desta, foram realizadas as seguintes etapas: determinação de que cada uma das perguntas corresponderia a uma variável, codificação das variáveis categóricas e elaboração de questões fechadas com respostas mais abrangentes e mutuamente exclusivas.

Análise estatística: Com base na análise estatística descritiva, foram determinados os valores de frequência para dados qualitativos e mediana com faixa de variação e desvio interquartil (DIQ) para variáveis quantitativas que não apresentam distribuição normal (teste de Kolmogorov-Smirnov). Para determinar a significância das diferenças observadas entre os dados dos subgrupos estudados (presença versus ausência de histórico de acidentes biológicos e presença versus ausência de participação prévia em cursos de biossegurança), foram consideradas a hipótese nula, ou $\mathrm{H}_{0}$ (ausência de diferença entre os dois subgrupos), e a hipótese alternativa ou, $\mathrm{H}_{1}$ (presença de diferença entre os dois subgrupos). Na análise bivariada, foi utilizado o teste Qui-Quadrado para amostras independentes e, quando apropriado, com correção de Yates para comparar frequência dos dados qualitativos e o teste $U$ de Mann-Whitney para as variáveis quantitativas que não apresentaram distribuição normal. Um valor de $\mathrm{P}<0,05$ (teste bicaudal) foi considerado estatisticamente significante. Todas as análises foram realizadas utilizando-se o pacote estatístico GraphPad Instat versão 3.05 (GraphPad Software, San Diego, Califórnia, EUA).

Aspectos éticos: Os dados foram coletados após consentimento verbal dos profissionais de saúde. Em conformidade aos princípios contidos na Resolução n 196/96 do Conselho Nacional de Saúde (Brasil), no que diz respeito à participação dos sujeitos na pesquisa: os mesmos foram esclarecidos, acerca dos objetivos do estudo, de que poderiam recusar a participar sem que isso implicasse em qualquer prejuízo; que tal participação não envolveria custo financeiro, e que não teriam qualquer dano. Também foram informados de que seria assegurado o seu anonimato na divulgação dos resultados desta pesquisa em eventos e periódicos científicos. 0 protocolo de pesquisa $n .^{\circ}$ 0079.0.317.000-08 foi aprovado pelo Comitê de Ética em Pesquisa da Universidade do Grande Rio Prof. José de Souza Herdy UNIGRANRIO (Rio de Janeiro).

\section{RESUL TADOS}

Neste estudo, foram coletados dados de uma amostra de 266 profissionais de saúde, dos quais 138 do sexo feminino $(51,9 \%)$ e 128 do sexo masculino (48,1\%), com idade mediana de 28 anos (17 a 69 anos; DIQ, 12 anos), sendo que a faixa etária mais prevalente $(84,6 \% ; n=225)$ foi a de 20 a 40 anos. Com relação ao nível de escolaridade, a maior parte (87,2\%; $n=232$ ) dos indivíduos estudados apresentava nível superior, com mediana de tempo de conclusão do curso de 4 anos ( 1 mês a 40 anos; DIQ, 8 anos). Do total de 266 indivíduos, $174(65,4 \%)$ relataram ter feito nos últimos dois anos algum curso de atualização em sua área e 106 (39,8\%) fizeram algum curso contendo temas de biossegurança.

Com relação ao conhecimento sobre acidentes biológicos, vírus e/ou bactérias foram relatados como os agentes infecciosos potencialmente transmissíveis durante 0 exercício de suas atividades profissionais por $162(60,9 \%)$, e $25(9,3 \%)$ não souberam responder. Além disso, $165(62,0 \%)$ indivíduos responderam serem as agulhas os instrumentos mais frequentemente implicados em acidentes perfurocortantes. A falta de atenção, o despreparo técnico e a não utilização de equipamentos de proteção individual (EPIs) e coletiva (EPCs) foram reportadas como as principais causas associadas aos acidentes perfurocortantes $(59,0 \% ; n=157)$.

Com relação ao histórico de acidentes biológicos sofridos pelos profissionais estudados, a ocorrência desses acidentes nos últimos cinco anos foi reportada em 31,9\% ( $n=85)$ dos indivíduos, com frequência ocasional (de 1 a 3 vezes) em 79/85 (92,9\%) sujeitos. Dentre aqueles que sofreram acidentes, 45 (52,9\%) informaram que o acidente foi com agulha e $34(40,0 \%)$ relataram que 0 acidente ocorreu durante 0 descarte ou lavagem de instrumentos perfurocortantes (Tabela 1).

Quanto ao cuidado local após o acidente biológico, observamos que $48(56,4 \%)$ dos profissionais relataram a lavagem da região afetada com água e sabão como primeira conduta. Realizar exames sorológicos para detecção de doenças infectocontagiosas (27\%; $n=23)$, procurar atendimento médico especializado ou não (11,7\%; $n=10)$ e proceder à notificação do acidente biológico $(9,4 \% ; n=8)$ foram referidos como principais cuidados gerais após 0 acidente biológico. Em relação à situação vacinal contra hepatite B, 246/266 $(92,4 \%)$ dos profissionais estudados relataram vacinação prévia; porém, somente $116(47,1 \%)$ dos profissionais vacinados realizaram testes sorológicos para avaliação da resposta vacinal (positividade para o marcador anti-HBs). Dentre os profissionais acidentados, 83 $(97,6 \%)$ relataram vacinação prévia contra hepatite B.

A frequência de uso de EPIs -jaleco, máscara, óculos e gorro - foi relatada por 250 (93,9\%), 177 (66,5\%), 135 (50,7\%) e 95 $(35,7 \%)$ dos profissionais estudados, respectivamente. Em relação às medidas de higiene, $233(87,6 \%)$ profissionais relataram o uso de 
antissépticos para lavagem das mãos, sendo que somente 63 (36,9\%) destes profissionais o fazem antes e após a realização de procedimentos. Os antissépticos mais utilizados (137/233; 58,7\%) pelos profissionaisforam os degermantes. Amaioria dos profissionais estudados $(216 / 266 ; 81,2 \%)$ realiza a descontaminação dos materiais após seu uso, sendo a autoclavagem o método de descontaminação mais frequentemente utilizado (141/216; $65,5 \%$ ). Aproximadamente metade dos profissionais (168/266; $63,1 \%$ ) relatou que realiza o descarte de materiais perfurocortantes em recipientes de paredes rígidas de papelão.
Na Tabela 1 são apresentadas as características dos profissionais de saúde estratificados de acordo com o histórico de acidentes ocupacionais envolvendo material biológico potencialmente infectante. Os profissionais que já sofreram acidente biológico apresentaram medianas de idade e tempo de conclusão de curso significativamente maiores do que aqueles sem história prévia de acidentes biológicos, além de terem o conhecimento de que agulhas são os objetos mais frequentemente envolvidos nos acidentes.

Tabela 1. Características dos profissionais de saúde em relação ao histórico de acidentes de trabalho com material biológico, estudados nos Municípios de Itaperuna, Campos dos Goytacazes e Rio de Janeiro, no período de janeiro/2008 a maio/2008 ( $n=266)$

\begin{tabular}{|c|c|c|c|}
\hline \multirow{2}{*}{ Característica } & \multicolumn{2}{|c|}{ Histórico de acidente biológico $n(\%)$} & \multirow[b]{2}{*}{ Valor de $P$} \\
\hline & $\begin{array}{l}\text { Presente } \\
(n=85)\end{array}$ & $\begin{array}{c}\text { Ausente } \\
(n=181)\end{array}$ & \\
\hline $1 . \operatorname{Sexo}$ & & & 0,9795 \\
\hline Masculino & $41(48,2)$ & $87(48,0)$ & \\
\hline Feminino & $44(51,8)$ & $94(52,0)$ & \\
\hline 2.Idade (anos) & & & 0,0001 \\
\hline Mediana & 32,0 & 27,0 & \\
\hline Mínimo & 17,0 & 20,0 & \\
\hline Máximo & 65,0 & 69,0 & \\
\hline 3.TCC (anos) & & & $<0,0001$ \\
\hline Mediana & 7,0 & 2,0 & \\
\hline Mínimo & 0,16 & 0,10 & \\
\hline Máximo & 36,0 & 5,0 & \\
\hline 4.Curso de Atualização & & & 0,2812 \\
\hline Sim & $60(70,5)$ & $114(62,9)$ & \\
\hline Não & $25(29,5)$ & $67(37,1)$ & \\
\hline 5.Curso de Biossegurança & & & 0,7125 \\
\hline Sim & $32(37,6)$ & $74(40,8)$ & \\
\hline Não & $53(62,4)$ & $107(59,2)$ & \\
\hline \multicolumn{4}{|l|}{ 6.Informação sobre AB: } \\
\hline 6.1. Agente infeccioso & & & 0,5132 \\
\hline Vírus & $29(34,1)$ & $52(28,7)$ & \\
\hline Bactérias & $23(27,1)$ & $58(32,0)$ & \\
\hline Vários & $25(29,4)$ & $45(24,9)$ & \\
\hline Fungos & $1(1,2)$ & $1(0,6)$ & \\
\hline Não sabe & $7(8,2)$ & $25(13,8)$ & \\
\hline 6.2.Principal instrumento & & & $<0.0001$ \\
\hline Agulha & $45(52,9)$ & $14(7,7)$ & \\
\hline Outros & $40(47,1)$ & $167(92,3)$ & \\
\hline 6.3.Principal causa & & & 0,4391 \\
\hline Desatenção & $39(45,8)$ & $87(48,0)$ & \\
\hline Despreparo & $6(7,1)$ & $7(3,9)$ & \\
\hline Não utilização de EPI & $6(7,1)$ & $7(3,9)$ & \\
\hline Outras & $34(40,0)$ & $80(44,2)$ & \\
\hline 7.Uso de EPI & & & 0,3360 \\
\hline Jaleco & $79(92,9)$ & $171(94,4)$ & \\
\hline Máscara & $56(65,8)$ & $121(66,8)$ & \\
\hline Óculos & $54(63,5)$ & $81(44,7)$ & \\
\hline Gorro & $34(40,0)$ & $61(33,7)$ & \\
\hline 8.Uso de antisséptico & & & 0,6768 \\
\hline Sim & $76(89,4)$ & $157(86,7)$ & \\
\hline Não & $9(10,6)$ & $24(13,3)$ & \\
\hline 9.Descontaminação de instrumentos & & & 0,8723 \\
\hline Sim & $70(82,3)$ & $146(80,6)$ & \\
\hline Não & $15(17,7)$ & $35(19,4)$ & \\
\hline
\end{tabular}


Na Tabela 2 são apresentadas as características dos profissionais de saúde estratificados de acordo com 0 histórico de participação em cursos de biossegurança. A amostra estudada de profissionais de nível superior era constituída, principalmente, de profissionais das áreas de biologia, bioquímica, enfermagem, farmácia, fisioterapia, fonoaudiologia, odontologia, medicina e medicina veterinária. Houve participação proporcional de profissionais de cada município no estudo, porém eles não informaram em que tipo de instituição trabalhava (pública ou privada). Os profissionais que já fizeram curso de biossegurança apresentaram idade mediana maior do que a dos profissionais que nunca participaram de curso dessa natureza. 0 tempo mediano de conclusão de curso foi significativamente maior naqueles profissionais que já haviam participado de curso de biossegurança. Dentre os profissionais que relataram já terem feito curso de biossegurança, foi observada também uma frequência significativamente maior de histórico de curso de atualização na sua área profissional, assim como do uso de EPIs, antissépticos e descontaminação de instrumentos.

Tabela 2. Características dos profissionais de saúde em relação ao histórico de participação em curso de biossegurança, estudados nos Municípios de Itaperuna, Campos dos Goytacazes e Rio de Janeiro, RJ, no período de janeiro/2008 a maio/2008 $(n=266)$

\begin{tabular}{|c|c|c|c|}
\hline \multirow[t]{2}{*}{ Característica } & \multicolumn{2}{|c|}{$\begin{array}{l}\text { Participação em curso de biossegurança nos últimos dois anos } \\
\qquad(2006 \text { a 2008) } n(\%)\end{array}$} & \multirow[t]{2}{*}{ Valor de $P$} \\
\hline & $\begin{array}{c}\operatorname{Sim} \\
(n=106) \\
\end{array}$ & $\begin{array}{c}\text { Não } \\
(n=160)\end{array}$ & \\
\hline Sexo & & & 0,7083 \\
\hline Masculino & $53(50)$ & $75(46,8)$ & \\
\hline Feminino & $53(50)$ & $85(53,2)$ & \\
\hline Idade (anos) & & & 0,1086 \\
\hline Mediana & 32,0 & 28,0 & \\
\hline Mínimo & 21,0 & 17,0 & \\
\hline Máximo & 62,0 & 69,0 & \\
\hline Categoria profissional & & & 0,1223 \\
\hline Biólogo & $7(6,6)$ & $4(2,6)$ & \\
\hline Dentista & $9(8,5)$ & $22(13,8)$ & \\
\hline Enfermeiro & $6(5,7)$ & $14(8,8)$ & \\
\hline Farmacêutico & $5(4,7)$ & $21(13,2)$ & \\
\hline Téc. de Laboratório & $19(17,9)$ & $29(18,1)$ & \\
\hline Outra & $60(56,6)$ & $92(57,5)$ & \\
\hline TCC (anos) & & & 0,0409 \\
\hline Mediana & 5,0 & 3,0 & \\
\hline Mínimo & 0,08 & 0,16 & \\
\hline Máximo & 30,0 & 40,0 & \\
\hline Curso de Atualização & & & $<0,0001$ \\
\hline Sim & $94(88,7)$ & $80(50)$ & \\
\hline Não & $12(11,3)$ & $80(50)$ & \\
\hline Histórico de AB & & & 0,7125 \\
\hline Sim & $32(30,2)$ & $53(33,1)$ & \\
\hline Não & $74(69,8)$ & $107(66,9)$ & \\
\hline Uso de EPI & & & 0,2931 \\
\hline Jaleco & $101(95,2)$ & $149(93,1)$ & \\
\hline Máscara & $80(75,5)$ & $97(60,6)$ & \\
\hline Óculos & $67(63,2)$ & $68(42,5)$ & \\
\hline Gorro & $38(35,8)$ & $57(35,6)$ & \\
\hline Uso de antisséptico & & & 0,0773 \\
\hline Sim & $98(92,4)$ & $135(84,3)$ & \\
\hline Não & $8(7,6)$ & $25(15,7)$ & \\
\hline Descontaminação de instrumentos & & & 0,2723 \\
\hline Sim & $90(84,9)$ & $126(78,7)$ & \\
\hline Não & $16(15,1)$ & $34(21,3)$ & \\
\hline
\end{tabular}




\section{DISCUSSÃO}

Os trabalhadores de saúde são expostos ao risco de acidentes ocupacionais envolvendo a exposição a materiais biológicos, pois manipulam diferentes materiais perfurocortantes e estão em contato com materiais e pacientes contaminados por micro-organismos patogênicos, incluindo HIV e vírus das hepatites $\mathrm{B}$ eC. A fim de reduzir o risco de acidentes, torna-se necessária a utilização de medidas de precaução universal (MPU), sendo que o uso das MPPs está intimamente relacionado à percepção que os profissionais possuem sobre os riscos a que estão expostos e a susceptibilidade a estes riscos. No grupo estudado, verificamos que a maioria dos indivíduos realizou um curso de atualização nos últimos dois anos, porém poucos realizaram cursos na área de biossegurança. Esta situação demonstra a importância da realização de capacitações em biossegurança entre os profissionais de saúde tal como foi realizada em algumas instituições brasileiras. ${ }^{11}$

No presente trabalho, observamos que a maioria dos profissionais de saúde reconheceu vírus e bactérias como os principais agentes infecciosos potencialmente transmissíveis durante o exercício de suas atividades profissionais (60,9\%). Contudo, outros patógenos também podem estar associados a acidentes biológicos, tais como fungos. A maioria $(62,0 \%)$ identificou as agulhas como os instrumentos mais frequentemente implicados em acidentes perfurocortantes. Entre os profissionais entrevistados, $30 \%$ dos indivíduos relataram acidente de trabalho previamente e, destes, $40 \%$ ocorreram devido ao manuseio de perfurocortantes. Estudos anteriores mostraram que a maioria dos acidentes de trabalho entre profissionais de saúde está associada ao manuseio de perfurocortantes. ${ }^{2,3,12,13}$ Os acidentes com perfurocortante provavelmente ocorrem durante o desencaixe ou reencape de agulhas, durante o descarte dos perfurocortantes ou, ainda, por movimentos abruptos seja do paciente ou do profissional de enfermagem ou de outra área da saúde., 3,14

A maioria dos indivíduos informou no preenchimento do questionário a falta de atenção, o despreparo técnico e a não utilização de equipamentos de proteção individual (EPIs) e coletiva (EPCs) como as principais causas de acidentes com perfurocortantes $(59,0 \%)$. A falta de atenção pode estar relacionada à sobrecarga de trabalho que deixa o profissional mais estressado, exigindo maior rapidez na execução de tarefas tal como foi observado entre os profissionais da equipe de resgate pré-hospitalar do Corpo de Bombeiros em Goiás. ${ }^{15}$ Neste mesmo estudo, os entrevistados relataram que a sobrecarga de trabalho, a falta de cursos específicos e a falta de EPIs são os maiores fatores relacionados à não adesão das medidas de precaução universal.

Em relação ao uso de EPI, a maioria dos profissionais entrevistados relatou o uso de jaleco enquanto o gorro foi o EPI menos relatado pelos profissionais. Pereira e colaboradores ${ }^{16}$ também constataram que os jalecos e máscaras são utilizados em percentual significativo, enquanto que o gorro nem sempre é utilizado. 0 jaleco deve ser preferencialmente descartável; caso seja reutilizável, deve ser limpo ao final do período de trabalho com água e sabão, evitando-se o contato com outras roupas de uso comum. Além disso, ele nunca deve ser utilizado fora do ambiente laboral. Dessa forma, são necessárias campanhas educativas para orientar os profissionais de saúde sobre o uso do jaleco.

Em relação às medidas de higiene, a maioria $(87,6 \%)$ relatou o uso de antissépticos para lavagem das mãos, porém somente $36,9 \%$ destes profissionais realizam a lavagem antes e após a realização de procedimentos. Uma possível explicação para este fato são os programas de capacitação que indicam a lavagem das mãos, mas frequentemente não relatam a necessidade de isso ser feito antes e após os procedimentos. Um estudo realizado entre anestesiologistas verificou que somente $12,9 \%$ dos profissionais realizavam a lavagem das mãos antes de procedimentos de punção venosa; 9,5\%, em entubação endotraqueal; e 14,3\%, em punção espinhal. ${ }^{17}$

Em relação à descontaminação dos materiais após seu uso, a maioria utiliza a autoclave do mesmo modo que foi observado por Pereira e colaboradores. ${ }^{17}$ Aproximadamente metade dos profissionais $(168 / 266 ; 63,1 \%)$ relatou que realiza o descarte de materiais perfurocortantes em recipientes de paredes rígidas de papelão, o que é extremamente importante para diminuir o risco de acidentes com perfurocortantes, principalmente entre os profissionais de limpeza. ${ }^{3}$

Outro achado importante foi a observação de que a maioria dos entrevistados reconhece as condutas apropriadas após o acidente biológico, pois relatou a lavagem da região afetada com água e sabão como primeira conduta. Porém, em relação às medidas gerais, poucos relataram a realização de exames sorológicos para detecção de doenças infectocontagiosas, a procura de atendimento médico especializado ou não e a notificação do acidente biológico. Esta situação impede que haja o conhecimento real da prevalência de acidentes de trabalho entre os profissionais de saúde. Além disso, observamos que a maioria dos indivíduos previamente acidentados está entre aqueles com idade mais avançada e com maior tempo de conclusão de curso, reforçando a importância da realização de cursos de biossegurança nesta população. Outro achado que corrobora esta observação foi o fato de que aqueles indivíduos que já fizeram curso de biossegurança também realizaram com maior frequência algum curso de atualização na sua área profissional, assim como referem utilizar EPls, antissépticos e descontaminação de instrumentos.

Os profissionais de saúde estão expostos a diferentes patógenos, e, por este motivo, é importante que estes profissionais sejam vacinados contra aqueles agentes para os quais existem vacinas disponíveis. A maioria dos profissionais entrevistados neste estudo $(92,4 \%)$ relatou vacinação contra a hepatite B tal como reportado por outros autores. ${ }^{12,17}$ Porém, 
somente $(47,1 \%)$ dos profissionais vacinados realizaram teste sorológico para avaliação da resposta vacinal (positividade para o marcador anti-HBs). Em estudo realizado por Pinheiro e Zeitoune, envolvendo todos ( $n=44$ ) os funcionários da equipe de enfermagem do setor de clínica médica de um hospital militar do Município do Rio de Janeiro, acerca do conhecimento destes profissionais sobre a hepatite $B$, foi constatado que a maioria $(72,7 \%)$ dos profissionais entrevistados não considerou necessária a avaliação sorológica para detecção de anticorpos protetores anti-HBs (soroconversão). Apesar de a vacina contra hepatite B apresentar alta taxa de soroconversão, principalmente em crianças, adolescentes e adultos sadios, está indicada a avaliação da soroconversão por meio da realização do teste sorológico anti-HBs, visando à demonstração de aquisição de títulos protetores desses anticorpos, principalmente em grupos de risco, tais como: imunocomprometidos e profissionais de saúde. ${ }^{18}$

\section{CONCLUSÕES}

Concluímos que a maioria dos profissionais reconhece e adota as medidas de precaução-padrão; no entanto, uma parcela pequena, porém significativa, adota de forma insuficiente ou não adotam tais medidas. Observamos que os indivíduos acidentados tinham maior mediana de idade e tempo de conclusão de curso, reforçando a necessidade de cursos de biossegurança principalmente neste grupo. Além disso, poucos profissionais notificaram os acidentes biológicos ocorridos, sugerindo que o número de acidentes entre os profissionais de saúde pode ser maior do que aquele apresentado nas bases de dados oficiais. Esta situação demonstra que a capacitação em biossegurança é um fator primordial para adoção das medidas de precaução-padrão, pois requerem nova aprendizagem e, principalmente, mudanças de hábitos com as quais muitos profissionais têm dificuldade de lidar.

Figura 1. Modelo de questionário sobre conhecimento e utilização de medidas de precaução universal (MPU) aplicado para profissionais de saúde do Estado do Rio de Janeiro

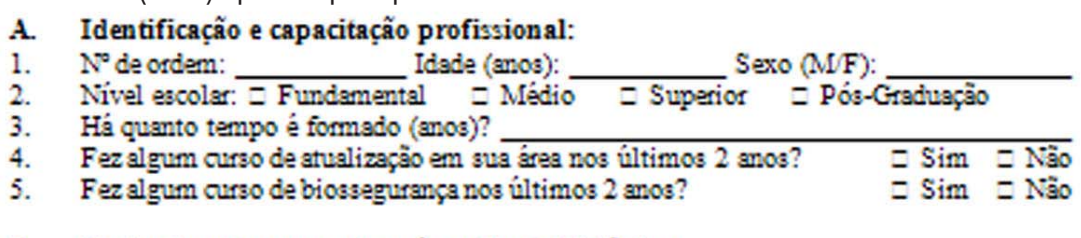

B. Conhecimento e suporte após acidente biológico:

1. Em sua opiniâo, quais micro-organismos podem ser transmitidos durante as suas atividades profissionais?

2. Em sua opiniäo, qual o instrumento que mais causa acidente perfurocontante durante as suas atividades profissionsis?

3. Em sua opiniäo, qual a principal cassa de acidente perfurocortante durante sa suas atividades profissionsis?

4. Já sofreu algum acidente perfurocortante com agulha ou outro material nos últimos 5 anos?

= $\operatorname{Sim} \quad$ = Naิo

4.1. Em caso afimativo, quantas vezes vocêjá sofreu acidente perfurocortante durante as suas atividades profissionsis?

4.2. Em caso afimativo, quantas vezes vocêjá sofieu acidente durante o descarte ou lavagem de instrumentos perfirocortantes?

5. Qual o primeiro cuidado local tomado após a exposição a qualquer material biológico?

6. Qual o primeiro cuidado geral tomado após a exposição a qualquer material biológico?

7. Já foi vacinadio contra hapatite $B$ ?

8. Já fez exame de angue para avaliar a resposta spós a vacinaçâo contra hepatite B?

= Sim = Nầ

C. Utilização de MPU em atividades profissionais:

1. Usa jalaco?

= $\operatorname{sim} \quad=$ Nà

2. Usa gorro?

= $\operatorname{Sim} \quad$ Näo

3. Uas máscara?

= Sim = Näo

4. Usa óculos de proteça?o?

$=\operatorname{Sim}=\mathrm{Nä0}$

5. Usa sntisséptico nas mäos?
- Sim
= Näo

6. Qual o tipo de antissáptico que você mais utiliza para desinfeç̧ào de mãos?

- Sabonete = Degermante

7. Com que frequếncia você lava as mâos no ambiente de trabalho?

8. Faz antissapsia no paciente antes do atendimento?
$\square \operatorname{Sim}$ = Nào

9. Descontamina instrumentos perfurocontantes após o seu uso?
= $\mathrm{Sim}$ = Nào

10. Qual o local de descarte de materisis perfurocortantes?

11. Qual método de esteriliza̧̧âo de material mais utilizado? 


\section{REFERÊNCIAS}

1 - Marziale MHP, Nishimura KYN, Ferreira MM. Riscos de contaminação ocasionados por acidentes de trabalho com material pérfuro-cortante entre trabalhadores de enfermagem. Rev Latino-am Enfermagem. 2004 jan/fev; 12 (1): 36-42.

2-Chiodi MB, Marziale MHP, Robazzi MLCC. Occupational accidents involving biological material among public health workers. Rev Latino-am Enfermagem. 2007 jul-/ago; 15 (4): 632-38.

3 - Silva JA, Paula VS, Almeida AJ, Villar LM. Investigação de acidentes biológicos entre profissionais de saúde. Esc Anna Nery. 2009 set; 13 (3): 508-16.

4- De Almeida ANG, Tipple AFV, Souza ACS, Brasileiro ME. Risco biológico entre os trabalhadores de enfermagem. Rev Enferm UERJ. 2009 out/dez; 17(4): 595-600.

5 - Ministério da Saúde (BR). Exposição a materiais biológicos. Brasilia(DF); 2006.

6 - García-Zapata MRC, Silva e Souza AC, Guimarães JV, Tipple AFV, Prado MA, García-Zapata MTA. Standard precautions: knowledge and practice among nursing and medical students in a teaching hospital in Brazil. Int I Infect Control [on- line] [citado 2010 Nov 13]; 2010; 6 (1): Disponivel em: http://www.ijic.info/article/view/4075/3721

7 - Sridhar MR, Boopathi S, Lodha R, Kabra SK. Standard precautions and post exposure prophylaxis for preventing infections. Indian J Pediatr. 2004 Jul;71(7): 617-25.

8 - Anuário Brasileiro de Proteção. Seção Estatísticas. 2010. Disponível em: http://www.segurancanotrabalho.eng.br/estatisticas/estacidmundo.pdf 9 - Ministério da Previdência Social (BR). Anuario Estatistico da Previdencia Social. Brasília(DF); 2007. Disponível em: http://www.previdencia.gov.br/ conteudoDinamico.php?id $=572$

10 - Ministério do Trabalho e Emprego (BR). Nr 32: Dispõe sobre a segurança e saúde no trabalho em serviços de saúde. Brasília(DF); 2008. Disponível em: http://www.mte.gov.br/legislacao/ normas_regulamentadoras/nr_32.pdf

11 - Pereira MEC, Jurberg C, Soeiro MNC, Borba CM. A estruturação do Programa de Capacitação Profissional de Biossegurança no contexto do projeto de modernização da gestão científica do Instituto Oswaldo Cruz. Saude Soc São Paulo 2010; 19(2): 440-48.

12- Deisenhammer S, Radon K, Nowak D, Reichert J. Needlestick injuries during medical training. J Hosp Infect. 2006 jul; 63 (3): 263-67.

13- Gir E, Caffer Netto J, Malaguti SE, Canini SRMS, Hayashida M, Machado AA. Accidents with biological material and immunization against Hepatitis $B$ among students from the health area. Rev Latino-am Enfermagem. 2008 maio/junho; 16 (3): 401-06.

14-Brevidelli MM, Cianciarullo TI. Análise dos acidentes com agulhas em um hospital universitário: situações de ocorrência e tendências. Rev Latinoam Enfermagem. 2002 nov/dez; 10 (6): 780-86.
15- Florêncio VB, Rodrigues CA, Pereira MS, Souza ACS. Adesão às precauções padrão entre os profissionais da equipe de resgate préhospitalar do Corpo de Bombeiros de Goiás. Rev Eletr Enferm [periódico on-line]. 2003; [citado 2010 nov 13]; 5(1): Disponível em: http:// www.fen.ufg.br/revista/revista5_1/adesao.html.

16- Pereira CV, Cyrino MAACG, Luiz MR, Carvalho AC, Almeida CN. Avaliação dos conhecimentos dos cirurgiões-dentistas em relação à biossegurança na prática clínica. Rev Clin Pesq Odontol 2005 jul/set; 2 (1): 19-21.

17- Pereira TM, Castro KF, Santos TO, Prado MA, Junqueira ALN, Teles AS, et al. Avaliação da adoção das medidas de precauções padrão em categorias específicas de profissionais de saúde. Rev Eletr Enferm. [periódico on-line]. 1999 ; [citado 2010 nov 12] Disponível em: http:// uww.fen.ufg.br/revista/revista1_1/Medidas.html.

18- Pinheiro J, Zeitoune RCG. Hepatite B: conhecimento e medidas de biossegurança e a saúde do trabalhador de enfermagem. Esc Anna Nery. 2008 jun; 12 (2): 258-64. 